\title{
Comparative anatomical study of the hyoid apparatus of Bosk's fringe-toed lizard and spotted fan-toed gecko (Squamata: Lacertidae and Phyllodactylidae)
}

Fatma A. Mahmoud ${ }^{1 *}$ (D, Ali G. Gadel-Rab², Samy A. Saber ${ }^{3}$, Boshra A. ElSalkh ${ }^{4}$, Asmaa A. El-Dahshan ${ }^{4}$ and Doaa I. Gewily ${ }^{4}$

\begin{abstract}
Background: The present study aimed to illustrate comparative morphological, histological, and functional variations of the hyoid apparatus of Acanthodactylus boskianus and Ptyodactylus guttatus.

Result: The hyoid apparatuses and musculature of the two investigated species are well-developed. The hyoid apparatuses exhibit high mobility with different articulation sites between their skeletal elements. The degree of ossification of the hyoid apparatus of gecko is more developed than that of the lacertid lizard. In P. guttatus, a well-developed synchondrosis articulation appears between the basihyoid and ceratobranchialis of the hyoid apparatus. Meanwhile, in A. boskianus, the articular ligament which appears between basihyoid and ceratobranchialis is less developed and also appears as a ligament connection between the two parts of hyoid cornua in which ligaments provide more mobility to the hyoid of lacertid lizard.

Conclusion: The results reflect a phylogenetically informative character about these clad and explain the different functional demands imposed on the hyoid apparatus as well as confirm the important role of hyoid apparatus in the movement of the tongue during the prey transport.
\end{abstract}

Keywords: Lizard, Gecko, Hyoid, Tongue, Articulation

\section{Background}

The tongue seems to be related to terrestrial lifestyle to facilitate the manipulation of food on land and allowed to occupy a wider range of habitats (Iwasaki, 2002). In vertebrates, the tongue supports the hyoid skeleton by acting as an integral part in facilitating the action of the tongue. The hyoid skeleton in reptiles has several morphological patterns depending upon the feeding habitats (Darwish, 2012; Jamniczky, Russell, Johnson, Montuelle, \& Bels, 2009; Schwenk, 1995; Sherbrooke, Scardino, deNys, \& Schwartzkopf, 2007). However, the hyolingual system for reptiles in general, which supports the posterior portion of the buccal floor with the larynx embedded, is importantly involved not only in drinking, food handling, and transport, but also in respiration (e.g.,

\footnotetext{
* Correspondence: M_f11_7@yahoo.com

${ }^{1}$ Department of Zoology, Faculty of Science, Assuit University, Assiut, Egypt Full list of author information is available at the end of the article
}

gular pumping and panting) and vocalization (Riede et al., 2015; Riede, Tokuda, \& Farmer, 2011).

Moreover, the difference of the structure of hyoid skeleton among reptile group and their ossifications could simply be induced by higher muscular forces which occur on it during the transport of food (Currey, 1984). The lingual muscle groups that attach on the hyoid apparatus are suggestive of an important role during the extraoral lingual extensions observed during chemoreception and drinking (Bels, Goosse, \& Kardong, 1993; Goosse \& Bels, 1992). However, the mechanisms of reptiles' tongue during protrusion or retraction in several reptilian species are still poorly understood. In the present study, two sympatric species with two different feeding strategies were selected: Acanthodactylus boskianus and Ptyodactylus guttatus. The present study compares the contribution of the hyoid system of the tongue and its associated muscles in these two 
species, to facilitate an understanding of the mechanical performance of the tongue during the feeding process.

\section{Materials and methods}

Four adult spotted fan-toed geckos, Ptyodactylus guttatus, and Bosk's fringe-toed lizard, Acanthodactylus boskianus, were collected from different regions of Sinai and were approved by the Ethical Committee of the Faculty of Science, Assuit University, and then brought into the comparative anatomy of vertebrate lab in the Zoology Department, Faculty of Science, Assuit University. For light microscopic investigation, two specimens of both species were sacrificed by ether anesthesia then separated the tongue from the lower jaw and fixed in 10\% neutral formalin for 2 days and prepared for paraffin embedding; serial sections of $7 \mu \mathrm{m}$ were prepared and then stained with hematoxylin and eosin, and Masson' trichromic and orcein stain for the detection of collagen and elastic fibers, respectively (Bancroft \& Gamble, 2002). For the investigation of the skeletal elements of the hyoid apparatus in two study species, we used the double staining with Alizarin red and Alcian blue procedure according to Salaramoli, Sadeghi, Gilanpour, Azarnia, and Aliesfehani (2015). Digital camera (U3CMOS14000KPA (USB2.0) and (Infinix $\times 556$ hot 4 pro-4G, 13Mega) was used to take the photo of hyoid apparatus, and the figures were prepared by outlining the anatomical preparations with the help of the camera lucida. All measurements were taken from digital photographs using the Image J software, and analysis was made using the Excel statistical package. Nomenclature of the skeletal structure of hyoid followed that given by Gnanamuthu (1937).

\section{Results}

The hyoid apparatus of both $P$. guttatus and A. boskianus consists of unpaired elongated lingual process (entoglossus, $\mathrm{Ep}$ ) as an extension of the body of hyoid (basihyoid, $\mathrm{BH}$ ), two pairs of ceratobranchialis I and II (CB), and two pairs of hyoid cornua. The two pairs of hyoid cornua represent the anterolateral pair (hypohyalis, $\mathrm{Hh}$ ) and posterolateral one (ceratohyalis, $\mathrm{CH}$ ).

In $P$. guttatus, the entoglossus process (Ep) constitutes the anterior unpaired triangular-shaped skeletal element of the hyoid skeleton (3.85 mm length) (Figs. 1a, b and 5). The histological investigation of the hyoid skeleton of $P$. guttatus exhibits that the entoglossus process is completely cartilaginous with pointed anterior tip and broad posterior base which merges posteriorly with the body of hyoid (Fig. 1b). The entoglossus process is enveloped by an elastic connective sheath as well as aggregation of adipocyte around the entire posterior part of this process (Fig. $2 \mathrm{a}-\mathrm{C}$ ). The entoglossus process supports the posterior two thirds of the tongue and provides an attachment site of the hyoglossus muscle (M.Hg). That muscle originates posteriorly as one pair of bundles and then divides anteriorly into two pairs of bundles: lateral hyoglossus and medial hyoglossus muscles. The hyoglossus muscle wraps with the verticalis muscle $(\mathrm{M} . \mathrm{Vr})$ ventral to the transversalis muscle (M.Tr) (Fig. 2a).

In $A$. boskianus, the entoglossus process is welldeveloped spindle-shaped and completely cartilaginous element which initiates just posterior to the furcation of the fore tongue and extends posteroventrally along the posterior parts of the tongue (mid- and hind-tongue) (4.55 mm length) (Figs. 2d, e and 5). The anterior pointed tip of the entoglossus process bends ventrally to be lying within the floor of the mouth (Fig. 2d). Histological investigation of the hyoid apparatus of $A$. boskianus revealed that the entoglossus process forms from the hyaline cartilage which is located between the two bundles of the hyoglossus muscle (M.Hg) that are wrapped by fibers of verticalis muscle (M.Vr) (Fig. 2e). Posteriorly, the entoglossus process of $A$. boskianus extends ventral to the trachea and dorsal to the verticalis muscle (Fig. 2f).

The body of hyoid (basihyoid, $\mathrm{BH}$ ) is the median part of the hyoid skeleton of both studied species. That part of hyoid skeleton merges anteriorly with the entoglossus process to form a single unpaired skeletal element.

In $P$. guttatus, the basihyoid has a narrow cartilaginous proximal portion (cartilaginous basihyoid, $\mathrm{CBH})(1.47 \mathrm{~mm}$ length) and broad distal part which forks to form pair of bony process (bony process of basihyoid, BBH) $(2 \mathrm{~mm}$ length) posteriorly (Figs. 1a, b and 5). The histological investigation of the posterior end of the proximal portion of basihyoid reveals the appearance of calcium in matrix and between the chondrocytes of hyaline cartilage (Figs. 3a, b and 6). The distal portion of the basihyoid articulates posterolaterally with the first ceratobranchialis (CBI) and hypohyalis $(\mathrm{Hh})$ through basi-ceratobranchialis ligament (Lig.BC) (Figs. 1a, b and 4b) and is fused posteromedially with the short cartilagenous element of the hyoid skeleton (second ceratobranchialis, CBII) (Fig. 1a, b). The basihyoid provides attachment sites of the muscle mandibulohyoideus 2 (M.mh2), sternohyoideus profundous (M.Sth.p), and sternohyoideus superficialis (M.Sth.s) (Fig. 6).

In $A$. boskianus, the basihyoid appears as a broad unit which is fused anteriorly with the entoglossus process and posteriorly with the second ceratobranchialis $(1.96 \mathrm{~mm}$ length) (Figs. 1c, d and 5). The anatomical investigation of the hyoid apparatus of $A$. boskianus reveals that the basihyoid initiates relatively posterior to the laryngeal region. Moreover, the broad basihyoid is connected laterally with the first ceratobranchailis and hypohyalis through the basi-ceratobranchialis ligament (Lig. BC) (Fig. 1c, d). The histological investigation of the hyoid apparatus of A. boskianus exhibits that the basihyoid is a completely cartilaginous process which is formed of hyaline cartilage 


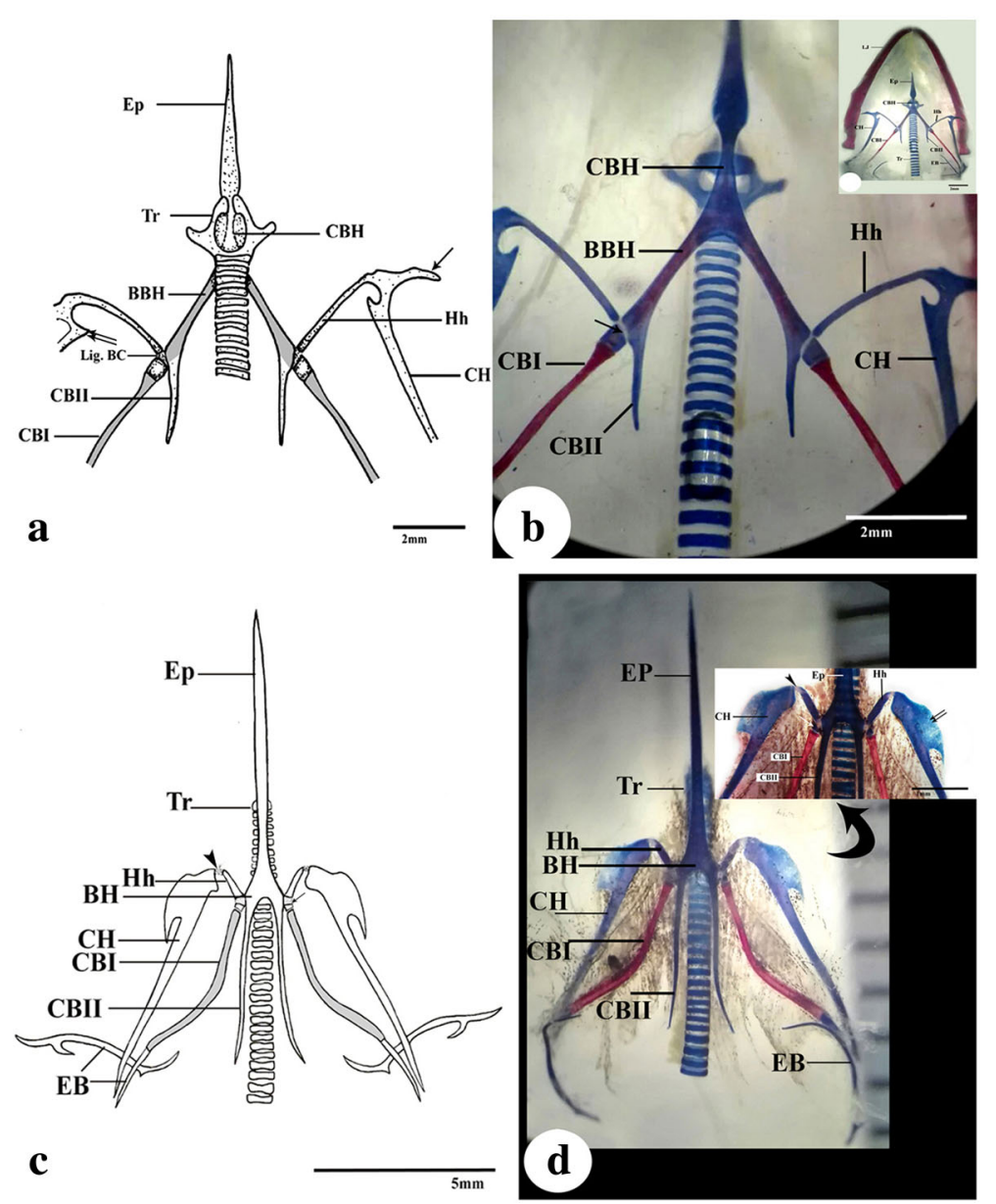

Fig. 1 a Dorsal view and $\mathbf{b}$ ventral view of the hyoid apparatus of $P$. guttatus showing its structure, basi-ceratbranchialis ligament, (Lig.BC), reduced cartilaginous extension (Arrow), and small medial process of the ceratohyalis (double arrows); scale bar $2 \mathrm{~mm}$. c, $\mathbf{d}$ Ventral view of the hyoid skeleton of $A$. boskianus showing the basi-ceratobranchialis ligament (arrow) and the cerato-hypohyalis ligament (arrowhead); Scale bar 2 and 5 mm. b, d Hyoid skeleton of both studied species stained with Alcian blue and Alizarin red stains showing all cartilaginous processes of the hyoid skeleton exhibited by a blue color while bony element stains by a red color. Ep, entoglossus process; $\mathrm{BH}$, basihyoid; $\mathrm{CBH}$, cartilaginous basihyoid; $\mathrm{BBH}$, bony basihyoid; $\mathrm{Hh}$, hypohyalis; $\mathrm{CH}$, ceratohyalis; CBI, ceratobranchialis l; CBII, ceratobranchialis II; Tr, trachea

envelops with collagenous sheath (Fig. 3d). The basihyoid of $A$. boskianus provides attachment sites of the muscles mandibulohyoideus 2 (M.mh2) and sternohyoideus profundous (M.Sth.p) (Fig. 3e).

The first ceratobranchialis (CBI) of both studied species is an elongated slender bony element that extends posterolaterally exceeding the posterior portion of the lower jaw (articular) to fuse posteriorly with the cartilaginous epibranchialis.

In $P$. guttatus, the first ceratobranchialis has a thick proximal end and narrow distal one $(4.55 \mathrm{~mm}$ length) (Figs.1a, b and 5). The proximal end of the first ceratobranchialis covers by a well-developing cartilaginous cap of hyaline cartilage to form synchondrosis articulation that articulates anteriorly with the posterior part of the basihyoid through basi-ceratobranchialis ligament (Lig.
BC) (Figs. 1b and 4b).The muscle mandibulohyoideus 2 (M.mh2) inserts along the ventromedial surface of the first ceratobranchialis(Fig. 4a).

In $A$. boskianus, the first ceratobranchialis (CBI) is a homogenous rod-like element which slightly curves laterally toward the lower jaw ( $3.795 \mathrm{~mm}$ length) (Figs. 1c, d and 5). The proximal end of that process is covered by a reduced cartilaginous cap that articulates with the basihyoid $(\mathrm{BH})$ and hypohyalis $(\mathrm{Hh})$ through basi-ceratobranchialis ligament (Lig. BC) (Fig. 1d). The first ceratobranchialis provides attachment sites for the muscles mandibulohyoideus 1, 2, and 3 (M.Mh 1, 2, and 3) and the muscle sternohyoideus profundous (M.sth.p) (Fig. 4c).

The second ceratobranchialis (CBII) of both investigated species is completely cartilaginous that is fused medially with the basihyoid. 


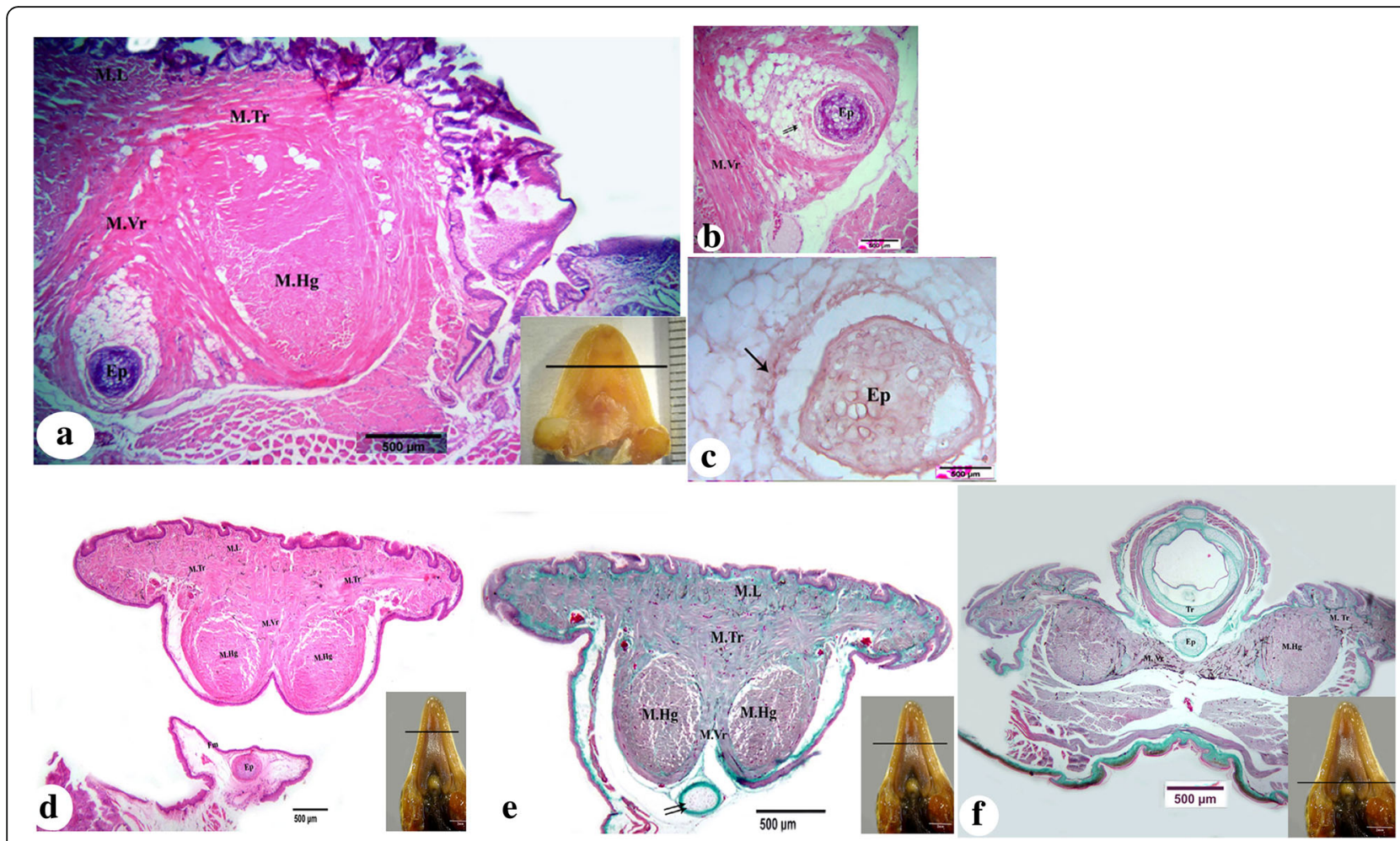

Fig. 2 a Photomicrograph of transverse section through the posterior half of the mid tongue of $P$. guttatus showing entoglossus (Ep), hypoglossus muscle (M.Hg), verticalis muscle (M. Vr), transveralis muscle (M.Tr), and tongitudinalis muscle (M.L). b, c High magnification shows fatty connective tissue (double arrows) and elastic fibers (arrow) around the entire posterior length of the entoglossus process (Ep). $\mathbf{d}$, e Photomicrograph of transverse section through the free portion and $\mathbf{f}$ through the posterior portion of the tongue of A. boskianus showing the position of entoglossus process (Ep) and its posterior extension ventral to the trachea $(\mathrm{Tr})$, topographic position of the hypoglossus $(\mathrm{M} . \mathrm{Hg})$, verticalis muscle $(\mathrm{M} . \mathrm{Vr})$, transveralis muscle (M.Tr), and collagen fibers (double arrow). b, d Stain by H\&E. c Stain by orcein. e, f Stain by Masson's trichromic stain. Scale bar $500 \mu \mathrm{m}$

In $P$. guttatus, the second ceratobranchialis appears as a short tapering rod on either side of the trachea $(1.55 \mathrm{~mm}$ length) (Figs. 1a, b and 5). Ventromedially, the second ceratobranchialis provides attachment sites of sternohyoideus profundous muscle (M.Sth.p) and sternohyoideus superficialis muscle (M.Sth.s) (Fig. 4a).

Meanwhile, in A. boskianus, the second ceratobranchialis (CBII) is a well-developed rod with pointed posterior end relatively equal in length with the first ceratobranchialis (3.23 mm length) (Figs. 1c, d and 5). The sternohyoideus profundous muscle inserts along the ventromedial surface of the first and second ceratobranchialis (Fig. 4c).

The hyoid cornua of both investigated species are made up of small anterolateral portion (hypohyalis, Hh) $(2.27 \mathrm{~mm}$ length in P. guttatus and $0.62 \mathrm{~mm}$ length in A. boskianus) which is connected medially with the basihyoid through basi-ceratobranchialis ligament (Lig. BC) and posterolateral one (ceratohyalis, $\mathrm{CH}$ ). The ceratohyalis is an elongated cartilaginous rod which extends parallel to the medial surface of the lower jaw (5.1 mm length in P. guttatus and $6.5 \mathrm{~mm}$ length in A. boskianus) (Figs. 1a, c, $\mathrm{d}$ and 16).

In $P$. guttatus, the proximal end of the ceratohyalis is completely fused with the hypohyalis (Fig. 1a, b), while in A. boskianus, the proximal end of that process is connected laterally with the hypohyalis through ceratohypohyalis ligament (Lig. CH) (Fig. 1c). Moreover, in $A$. boskianus, the proximal end of ceratohyalis has a flat cartilaginous expansion which appears broader than that of P. guttatus. Posteriorly, the ceratohyalis of both species becomes narrow and curves dorsally to the nuchal region (Fig. 1a, c, d).

\section{Discussion}

The tongue of both studied species, $A$. boskianus and $P$. guttatus, is supported with well-developed hyoid apparatus which moves by contraction of their muscles. The variations in form and degree of ossification of the hyoid apparatus increase the mechanical performance of the tongue among the two investigated species during prey transport. Both studied species depend on fast bite to seize their prey by using their jaws and then come to the role of tongue to transport the prey toward the buccal cavity. The observation of feeding behavior of these investigated species confirmed that these species are using different strategies during catching their prey and continue by several protraction-retraction motions of the 


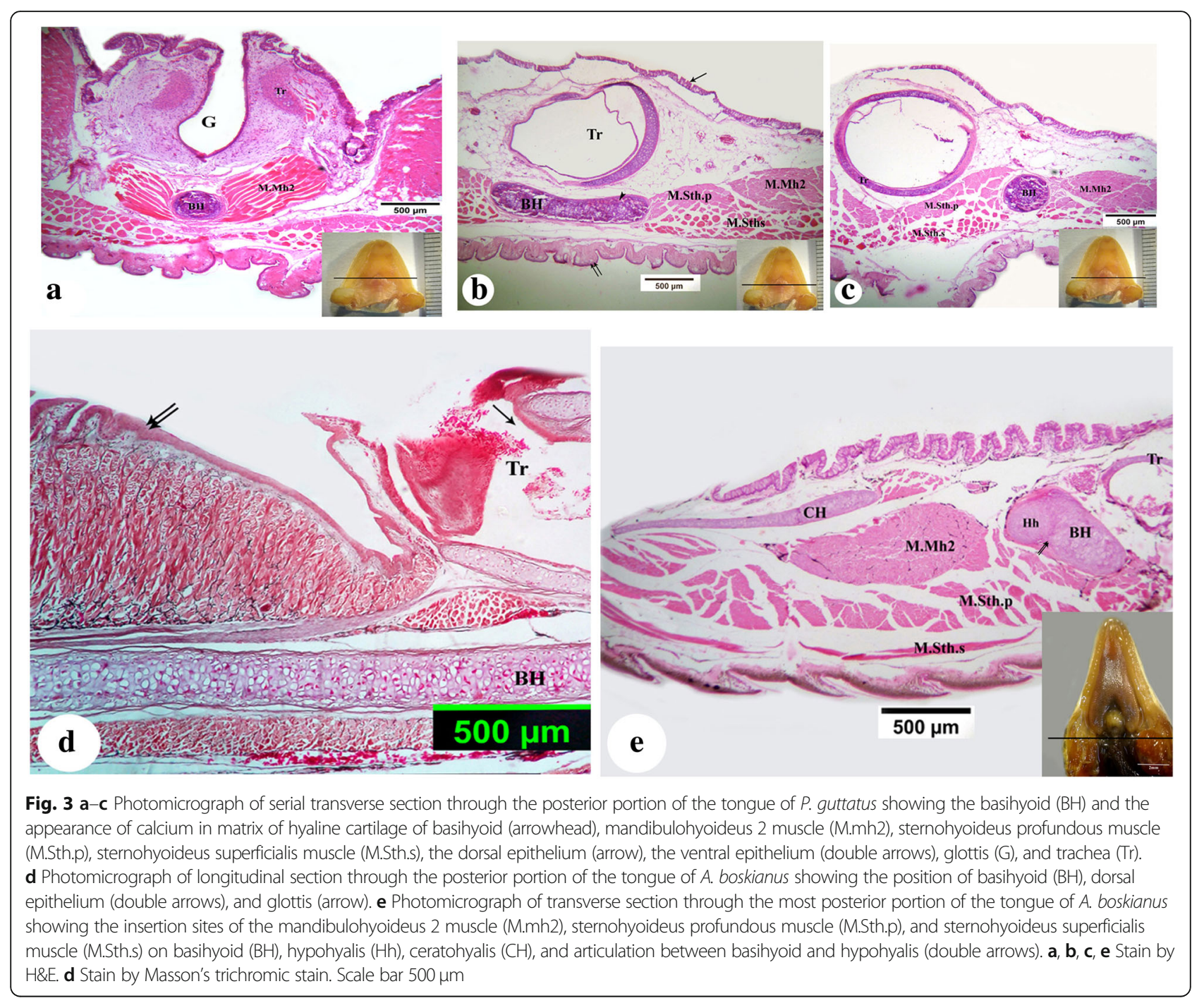

tongue like most of the lacertid lizards. Saber, Bashandy, Kawashti, and Sadek (1994) said that the Bosk's fringetoed lizard is a diurnal insectivorous species foraging in open area with sparse vegetation adopting active search strategy to find food, while P. guttatus (gecko) is a diurno-nocturnal species, feeding on insects and adopting a "sit and wait" strategy.

However, the different movement of the tongue of both studied species depends mainly on the position and structure of the hyoid apparatus as well as the distribution of their musculature. In $A$. boskianus, the tongue which has forked anterior tip and seems to be used as chemoreceptor in addition to capture prey supports with elongated cartilaginous entoglossus process just posterior to the furcation of the fore tongue then leaves the tongue and bent to lying ventrally in the floor of the mouth. Between the jaws, rami present the genioglossus muscle which attached on jaw symphysis and inserts on the entoglossus process. This muscle shares in protraction of the tongue outside the mouth (Herrel, Canbek, Ozelmas, Uyanoglu, \& Karakaya, 2005). The present authors suggested that the bending position of the entoglossus process may decrease the distance between the origin and insertion of the genioglossus muscle resulting in the maximization of the protraction force of the tongue.

Mechanically, that bending is allowed by the action of the paired muscle hyoglossus which is assisted by the bendable lingual nail. The net force of bending of the entoglossus allows bending the movable free portion of the tongue and helps in catching preys. Moreover, the entoglossus process is wrapped by an intrinsic lingual muscle group (verticalis, transversalis, and longitudinalis muscles). The development of lingual muscle groups is propositive of an important role the lingual extensions exhibit during chemoreception and drinking (Bels et al., 1993; Goosse \& Bels, 1992). Moreover, the contractions of the transverse intrinsic muscle groups will tend to protract the tongue as a result of its hydrostatic nature 

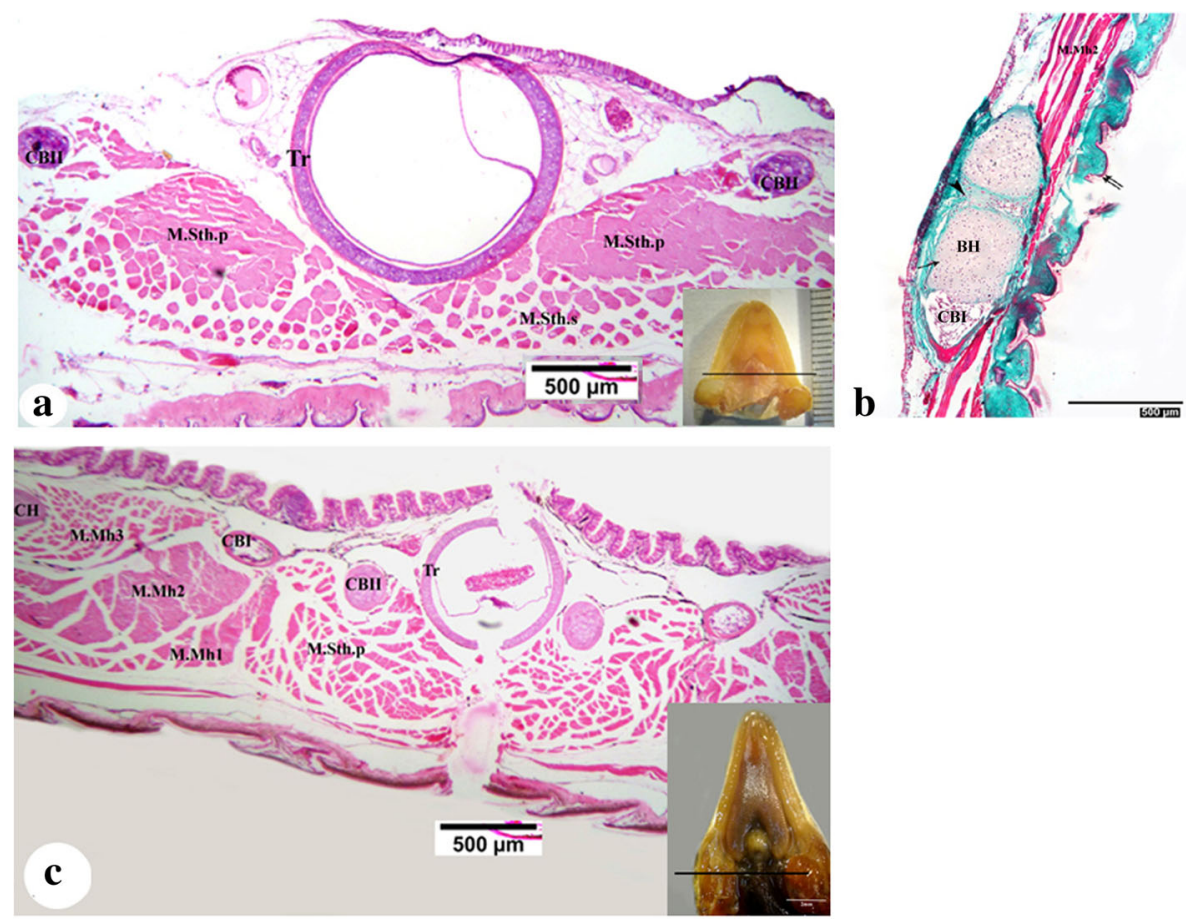

Fig. 4 Photomicrograph of $\mathbf{a}$ transverse section and $\mathbf{b}$ longitudinal section through the posterior portion of the tongue of $P$. guttatus showing the second ceratobranchialis (CBII), trachea ( $\mathrm{Tr}$ ), and synochrosis articulation between basihyoid and ceratobranchialis (CBI) through basi-ceratobranchialis ligament (arrowhead) and ventral epithelium (double arrows). c Photomicrograph of transverse section through the most posterior portion of the tongue of $A$. boskianus showing the attachment sites of the muscle mandibulohyoideus 1(M.mh1), muscle mandibulohyoideus 2 (M.mh2), muscle mandibulohyoideus 3(M.mh3), and muscle sternohyoideus profundous (M.Sth.p) on ceratohyalis (CH), ceratobranchialis I (CBI), and ceratobranchialis II (CBII). a, c Stain by H\&E. b Stain by Masson's trichromic stain. Scale bar $500 \mu \mathrm{m}$

(Kier \& Smith, 1985; Smith, 1988), and the longitudinal intrinsic and hyoglossal muscles can allow retraction of the tongue backward. The intrinsic tongue muscles presumably also play an additional and important role during prey transport.
Orientation of the position of the entoglossus process in $A$. boskianus at the level of laryngeal region, where it is located ventral to the trachea, dorsal to the intrinsic lingual muscle (verticalis) and retractor lingual muscle (hyoglossus) is associated with the changes in the

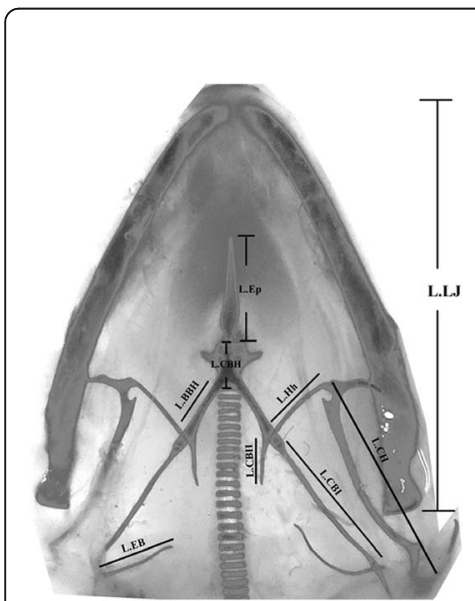

P. guttatus

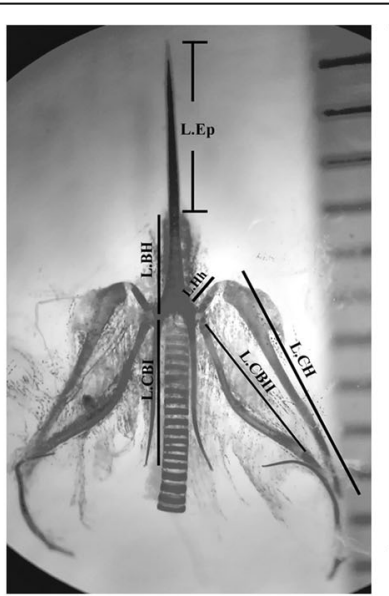

A.boskianus

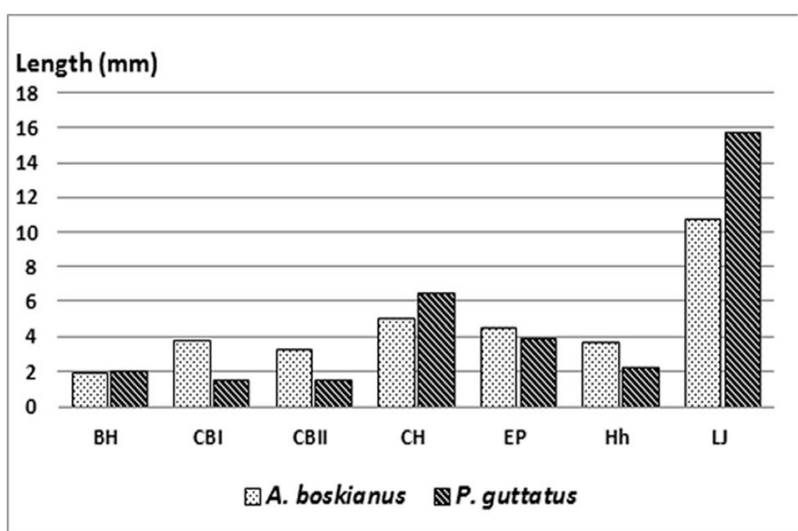

Fig. 5 Morphometrical characterization of each element of the hyoid apparatus of the two studied species. Means in millimeter, $N=10$. L.Ep, length of entoglossus process; L.BH, length of basihyoid; L.CBH, length of cartilaginous basihyoid; L.BBH, length of bony basihyoid; L.Hh, length of hypohyalis; L.CH, length of ceratohyalis; L.CBI, length of ceratobranchialis I; L.CBII, length of ceratobranchialis I; L.EB, length of epibranchialis 
morphology and use of the entoglossus process as observed in chameleons (Meyers, Herrel, \& Birch, 2002).

Meanwhile, the entoglossus process of the hyoid system of P. guttatus is a short cartilaginous element of hyaline type, with an anterior pointed tip and posterior broad one. That process is wrapped by the retractor hyoglossus muscle that formed from two pairs of bundles anteriorly. The well-developed retractor hyoglossus muscle with great bundle mass may be important for the fast protraction and retraction of the tongue of these species that feed on insects adopting a "sit and wait" strategy.

Physically, the hyaline cartilage and its enveloping elastic sheath and adipose connective tissue give the tongue the ability of bending and temporary deformation due to the action of several intrinsic lingual muscles. Also, it is more resistant to the load and weight forces acting on it than the elastic and fibrous cartilage. Bock (1974) confirmed that the cartilaginous tissues can withstand compressive forces, but unlike bony ones, the cartilage deforms under stress.

The basihyoid process exhibits great differences in the two studied species; in A. boskianus, it seems short and completely cartilaginous, while it is formed from two portions in $P$. guttatus: an anterior cartilaginous part and a posterior ossified one. Moreover, the cartilaginous second ceratobranchialis of the hyoid apparatus of $A$. boskianus is longer than that of P. guttatus. The variation in structure and degree of ossification in the hyoid processes is suggestive of functional difference in the use of the hyoid apparatus among the two studied species during prey transport. Interestingly, in another species of lacertid lizard, Lacerta viridis, the cortex of the ceratohyalis, hypohyalis, and first and second pair of ceratobranchialis was ossified (Bels, Chardon, \& Kardong, 1994). However, the A. boskianus as lacertid has different clad from P. guttatus (phyllodactylid); the present study reveals that the phyllodactylid species have more advanced hyoid apparatus than the lacerid lizard. Alternatively, the hyoid apparatus of both species could be subjected to variable functional demands on the hyoid system and ossifications could simply be induced by higher muscular forces exerted on the hyoid system during prey transport (Currey, 1984). Accordingly, the present authors suggest a more prominent role of the hyoid system during prey transport in these lizards. Clearly, this should be investigated further by examining both the degree of ossification and the functional role of the hyoid system during different behaviors in a broad sample of reptiles.

Single synchondrosis articular ligament is welldeveloped between the bony part of the basihyoid and the first ceratobrancialis in P. guttatus. That type of articulation resembles two epiphyseal growth plates back to back, but with a common central zone of resting cells.
Because of this arrangement, synchondrosis is exquisitely adapted to resist pressure and cause a marked range of motion reduction (Youngson, 2005).

Meanwhile, an articular ligament exhibited between the first ceratobranchialis, basihyalis, and hypohyalis and another ligament between the ceratohyalis and hypohyalis are exerted. These ligaments provide motion force for the hyoid processes allowing free protraction and retraction of the tongue.

Moreover, in both study species, it is shown that the basihyoid provides an attachment site of the hyoid protractors and that muscle mandibulohyoideus 2 may be used to extend the hyoid and effect on the movement of the tongue out the oral cavity during capture.

The present study indicates that in P. guttatus, the second ceratobranchialis provides an attachment site of hyoid retractor sternohyoideus profundous muscle which also attaches on the medial surface of basihyoid dorsal to hyoid retractor sternohyoideus superficialis muscle. In A. boskia$n u s$, the sternohyoideus profundous muscle inserts only along the ventral surface of basihyoid and the medial surface of the first ceratobranchialis. These muscles are associated with the use of the hyoid apparatus as retractor muscle in the two studied species but have different position and attachment as observed in lacertid lizards (Herrel et al., 2005).

\section{Conclusion}

The Bosk's fringe-toed lizard, A. boskianus, and spotted fan-toed geckos, $P$. guttatus, possess a high mobile hyoid apparatus with powerful musculature system. In P. guttatus, the degree of ossification of the hyoid apparatus and synchondrosis articulation between the basihyoid and ceratobranchialis is well-developed than that of $A$. boskianus. The difference in the shape, position, and structure of the hyoid apparatus affects directly on the movement of the tongue of $A$. boskianus and P. guttatus and also determines the functional performance of the tongue during prey capture.

\section{Acknowledgments \\ We would like to express our thanks to the comparative anatomy of vertebrate laboratory and microscopical unit in the Zoology Department, Faculty of Science,} Assiut University, for their help in specimen preparations.

\section{Authors' contributions}

SAS, AGG, FM, BAE, SED, and DIG designed and performed this work. All authors read and approved the final manuscript.

\section{Funding}

No funding sources

Availability of data and materials

No dataset was analyzed in the current study.

Ethics approval and consent to participate Not applicable

Consent for publication

All authors agree to the publication. 


\section{Competing interests}

The authors declare that they have no competing interests.

\section{Author details}

'Department of Zoology, Faculty of Science, Assuit University, Assiut, Egypt. ${ }^{2}$ Department of Zoology, Faculty of Science, Al-Azhar University, Assiut,

Egypt. ${ }^{3}$ Department of Zoology, Faculty of Science, Al-Azhar University, Cairo, Egypt. ${ }^{4}$ Department of Zoology, Faculty of Science (Girls), Al-Azhar University, Cairo, Egypt.

Received: 16 February 2019 Accepted: 28 May 2019

Published online: 26 June 2019

\section{References}

Bancroft, J. D., \& Gamble, M. (2002). Theory and practice of histological techniques, (5th ed., pp. 150-152). London: Churchill Livingstone.

Bels, V. L., Chardon, M., \& Kardong, K. V. (1994). Biomechanics of the hyolingualsystem in squamata. In V. L. Bels, M. Chardon, \& P. Vandewalle (Eds.), Biomechanics of feeding in vertebrates, (pp. 197-240). Berlin: Springer Verlag.

Bels, V. L., Goosse, V., \& Kardong, K. V. (1993). Kinematic analysis of drinking by the lacertid lizard, Lacerta viridis (Squamates, Scleroglossa). Journal of Zoology (London), 229, 659-682. https://doi.org/10.1111/j.1469-7998.1993.tb02663.x.

Bock, J. (1974). The avian skeleto-muscular system. In S. Farner, \& R. King (Eds.), Avian biology, (pp. 119-257). London and New York: Academic.

Currey, J. (1984). The mechanical adaptations of bones. Princeton: Princeton University Press.

Darwish, S. T. (2012). Comparative histological and ultrastructural study of the tongue in Ptyodactylus guttatus and Stenodactylus petrii (Lacertilia, Gekkonidae). Journal of American Science, 8(2), 603-612 http://www.jofamericanscience.org/ journals/am-sci/am0802/084_8055am0802_603_612.pdf.

Gnanamuthu, C. P. (1937). Comparative study of the hyoid and tongue of some typical genera of reptiles. Proceedings of the Zoological Society Series B, 107, 1-63.

Goosse, V., \& Bels, V. L. (1992). Kinematic analysis of tongue movements during chemosensory behaviour in the European green lizard, Lacerta viridis (Reptilia: Lacertidae). Candian Journal of Zoology, 70, 1886-1896. https://doi. org/10.1139/292-257.

Herrel, A., Canbek, M., Ozelmas, U., Uyanoglu, M., \& Karakaya, M. (2005). Comparative functional analysis of the hyolingual anatomy in lacertid lizards. The Anatomical Record, 284(A), 561-573. https://doi.org/10.1002/ar.a.20195.

Iwasaki, S. (2002). Evolution of the structure and function of the vertebrate tongue. Journal of Anatomy, 201, 1-13. https://doi.org/10.1046/j.1469-7580. 2002.00073.x.

Jamniczky, H. A., Russell, A. P., Johnson, M. K., Montuelle, S. J., \& Bels, V. L. (2009). Morphology and histology of the tongue and oral chamber of Eublepharis macularius (Squamata: Gekkonidae).with special reference to the foretongue and its role in fluid uptake and transport. Evolution Biology, 1-10. https://doi. org/10.1007/s1 1692-009-9072-9.

Kier, W. M., \& Smith, K. K. (1985). Tongues, tentacles and trunks: The biomechanics of movement in muscular hydrostats. Zoological Journal of the Linnean Society, 83, 307-324. https://doi.org/10.1111/j.1096-3642.1985.tb01178.x.

Meyers, J. J., Herrel, A., \& Birch, J. (2002). Scaling of morphology, bite force, and feeding kinematics in an iguanian and a scleroglossan lizard. In P. Aerts, K. D'Aout, A. Herrel, \& R. Van Damme (Eds.), Topics in functional and ecological vertebrate morphology, (pp. 47-62). Maastricht: Shaker Publishing.

Riede, T., Li, Z., Tokuda, I. T., et al. (2015). Functional morphology of the Alligator mississippiensis larynx and implications for vocal production. The Journal of Experimental Biology, 218, 991-998. https://doi.org/10.1242/jeb.117101.

Riede, T., Tokuda, I. T., \& Farmer, C. G. (2011). Subglottal pressure and fundamental frequency control in contact calls of juvenile Alligator mississippiensis. The Journal of Experimental Biology, 214, 3082-3095. https:// doi.org/10.1242/jeb.051110.

Saber, S. A., Bashandy, M. A., Kawashti, I. S., \& Sadek, A. G. (1994). Feeding ecology of two sympatric lizards, Acanthodactylus boskianus asper (Lacertidae) and Ptyodactylus guttatus (Gekkonidae) from WadiDigla, Eastern Desert, Egypt. Bulletin - Zoological Society of Egypt, 42, 187-206.

Salaramoli, J., Sadeghi, F., Gilanpour, H., Azarnia, M., \& Aliesfehani, T. (2015). Modified double skeletal staining protocols with Alizarinred and Alcian blue in laboratory animals. J ajaums ac ir, 13, 76-81 http://journals.ajaums.ac.ir/ files/site1/user_files_44b4b44/farzanesadeghi_vet-A-10-2497-1-f76349b.pdf.
Schwenk, K. (1995). Of tongues and noses: chemoreception in lizards and snakes. Trends in Ecology and Evolution, 10, 7-12. https://doi.org/10.1016/S01695347(00)88953-3.

Sherbrooke, W. C., Scardino, A. J., deNys, R., \& Schwartzkopf, L. (2007). Functional morphology of the scale hinges used to transport water: Convergent drinking adaptations in desert lizards (Moloch horridus and Phrynosom acornutum). Zoomorphology, 126, 89-102. https://doi.org/10.1007/s00435007-0031-7.

Smith, K. K. (1988). Form and function of the tongue in agamid lizards with comments on its phylogenetic significance. Journal of Morphology, 196, 157171. https://doi.org/10.1002/jmor.1051960205.

Youngson, R. M. (2005). Collins Dictionary of Medicine. Published by Harper Collins.

\section{Publisher's Note}

Springer Nature remains neutral with regard to jurisdictional claims in published maps and institutional affiliations.

\section{Submit your manuscript to a SpringerOpen ${ }^{\circ}$ journal and benefit from:}

- Convenient online submission

- Rigorous peer review

- Open access: articles freely available online

- High visibility within the field

- Retaining the copyright to your article

Submit your next manuscript at $\boldsymbol{\nabla}$ springeropen.com 